\title{
O teatro de revista na Madeira (1909- -1959): espaços, temas e protagonistas de um repertório regional
}

\author{
PAULO ESTEIREIRO E ROGÉRIO BARROS
}

\begin{abstract}
In the investigations carried out in the periodicals of the first half of the twentieth century, it became clear that one of the repertoires frequently performed in Madeira Island was the theatrical revue. This is an area that has not yet been studied, but it seems to be possible to argue that, between 1909, the year in which the first theater of the Madeiran authors' theatrical revue was known, and the beginning of the 1960s, dozens of original theatrical revues were produced in Funchal. This study intends to divulge a collection that is thought to be unpublished about the dynamization of theatrical revues in Madeira.
\end{abstract}

THEATRICAL REVUE / MADEIRA ISLAND / REGIONAL IDENTITY

Nas investigações realizadas nos periódicos da primeira metade do século $\mathrm{xx}$, tornou-se claro que um dos repertórios frequentemente executados nos teatros funchalenses era o teatro de revista. Em simultâneo, nas coleções de música manuscrita com composições da época a que tivemos acesso, encontrou-se também um conjunto de peças musicais de autores madeirenses, pertencentes a teatros de revista levados à cena na Madeira. Sendo uma área ainda pouco estudada, parece ser possível defender que, entre 1909, ano em que se conhece o primeiro teatro de revista de autores madeirenses, e o início da década de 1960, foram produzidas no Funchal dezenas de revistas originais, em espetáculos que juntavam escritores, compositores, atores, cenógrafos, encenadores e coreógrafos regionais. ${ }^{1}$

Enquanto a nível nacional se verifica um conjunto de estudos relevantes sobre o teatro de revista (Rebello, 1984-1985; Berjeaut, 2005; Santos, 2009), na Madeira não existe ainda qualquer investigação sobre este tipo

1 Em conversas informais realizadas na Madeira, apercebemo-nos de que havia a crença de nunca ter havido tradição de teatro de revista no Funchal. Esta investigação pretende desmistificar esta ideia e demonstrar a existência deste repertório original. 
de repertório. Apesar disso, registam-se algumas pesquisas que, de forma indireta, fazem referência à realização de teatros de revista na Madeira, sendo justo salientar a monografia 100 Anos do Teatro Municipal (Carita/ /Melo, 1988), o livro Registo Biobibliográfico de Madeirenses (Clode, 1983) e a publicação 50 Histórias de Músicos na Madeira (Esteireiro, 2008), para demonstrar que não se trata de um campo completamente inexplorado.

Neste contexto, considerou-se possível e pertinente fazer uma investigação sobre este repertório, procurando definir as características que distinguem um teatro de revista, saber em que espaços se produziu este tipo de repertório na Madeira, identificar os principais músicos e artistas envolvidos, e os temas prediletos selecionados para as revistas madeirenses.

Com estes propósitos, fez-se uma pesquisa nos periódicos da época, consultaram-se os programas de algumas revistas e editaram-se algumas partituras. Pretende-se divulgar um acervo que se pensa ser inédito sobre a dinamização do teatro de revista na Madeira. Por outro lado, supõe-se que a análise da produção deste género de espetáculos possa configurar um contributo para a compreensão da matriz sociocultural da época, dos seus intervenientes e costumes, estimulando, desta forma, a promoção e valorização do património cultural material e imaterial. Para divulgar os resultados desta investigação, estruturou-se este artigo em quatro partes distintas: o conceito de teatro de revista e o seu surgimento na Madeira; os temas prediletos; os principais espaços de produção; os autores relevantes.

\section{O TEATRO DE REVISTA: UM GÉNERO FRAGMENTADO}

$\mathrm{Na}$ primeira metade do século $\mathrm{xx}$, época áurea do teatro de revista madeirense, o conceito de revista já era muito diferente do preponderante em meados do século xx. Enquanto, em 1860, Andrade Ferreira definia o género como «um resumo dos acontecimentos que deram uma fisionomia especial ao decurso do ano» (Ferreira, 1860), no início do século xx, no Dicionário do Teatro Português, Sousa Bastos alargava a definição, classificando a revista como «género de peças em que o autor critica costumes dum país ou duma localidade, ou então faz passar à vista todos os principais acontecimentos do ano findo: revolução, grandes eventos, modas, acontecimentos artísticos ou literários, espetáculos, crimes, desgraças, etc.» (Bastos, 1908). 
Basicamente, o teatro de revista assume ao longo do tempo o lugar de um género de espetáculo único e diferente, constituído por números falados, musicais, coreográficos e humorísticos. Este género alcançou grande popularidade, por ter um cunho em que os espectadores facilmente se identificavam com aspetos do seu quotidiano. A revista teve inicialmente como linha orientadora o vaudeville (Rebello, 1984: 26), modelo francês de teatro orquestrado com forte componente musical, que consiste numa ligação de quadros independentes, característica marcante de uma estrutura fragmentada do género.

$\mathrm{Na}$ Madeira, é possível observar esta estrutura formal de revista fragmentada, em atos, quadros e apoteose, a qual se manteve regular ao longo da primeira metade do século xx. De acordo com os dados recolhidos (ver Quadro 1), na maior parte das peças em que foi possível observar a estrutura formal, esta divide-se em dois atos, com uma média de oito quadros, variando as apoteoses entre uma e três. Relativamente às músicas, o panorama é um pouco mais heterogéneo, registando-se revistas que contaram com 16 números musicais e outras constituídas por quase o triplo -45 .

No Quadro 1, apresentam-se alguns exemplos da estrutura típica dos espetáculos de revista a que nos referimos, onde fica clara a estrutura fragmentada do género:

\begin{tabular}{|c|c|c|c|c|c|c|}
\hline REVISTA & ATOS & QUADROS & MÚSICAS & APOTEOSE & PRÓLOGO & PERSONAGENS \\
\hline A Madeira por dentro & 2 & 6 & 25 & 2 & 1 & $\mathrm{~s} / \mathrm{d}$ \\
\hline Semilha e alface & 2 & 8 & 32 & 2 & $s / d$ & $s / d$ \\
\hline Carnaval & 2 & 8 & 20 & 1 & $s / d$ & $s / d$ \\
\hline S'tá quieta & 2 & 9 & 25 & & $s / d$ & $s / d$ \\
\hline Flores da Madeira & 2 & 8 & 27 & 2 & $s / d$ & $s / d$ \\
\hline Bolas de sabão & 2 & 9 & 32 & $s / d$ & $s / d$ & $s / d$ \\
\hline Sciencia Nova & 3 & 9 & 45 & 3 & 1 & $s / d$ \\
\hline O Reino da Bolha & 1 & 4 & 11 & 1 & 1 & 30 \\
\hline Miúdos & 2 & 8 & 32 & 2 & $\mathrm{~s} / \mathrm{d}$ & 120 \\
\hline A Madeira em festa & 1 & 4 & 16 & $s / d$ & 1 & $s / d$ \\
\hline $\begin{array}{l}\text { A Madeira na } \\
\text { berlinda }\end{array}$ & 3 & 12 & 32 & $\mathrm{~s} / \mathrm{d}$ & $\mathrm{s} / \mathrm{d}$ & $\mathrm{s} / \mathrm{d}$ \\
\hline
\end{tabular}


O facto de, inicialmente, ter uma componente literária, cuja «qualidade deixava muito a desejar», como refere Luiz Francisco Rebello, permitia, no entanto, ter uma audiência mais alargada e popular, principalmente quando aliada ao elemento musical. Muitos autores de revista acreditavam que, desta forma, seria mais fácil dar vida à revista e transmitir eficientemente a mensagem subjacente a cada tema das várias revistas (Rebello, 1984: 18).

Na Madeira, ao longo da segunda metade do século XIX, aparecem, pontualmente, as primeiras referências à representação de teatro de revista. Regista-se, por exemplo, em 1869, a realização, no Theatro Esperança, de uma récita em benefício do Cofre da Associação de Beneficência do Funchal, em que se representou a Revista a Galope do ANNO de 1864, referida como um «entreacto cómico em um acto» (Voz do Povo, 28/10/1869: 4), aparecendo no programa entre um drama em três atos e uma comédia:

Theatro Esperança - Sociedade Recreio Artistico. Sabbado 30 de Outubro de 1869. Recita a beneficio do cofre da Associação de Beneficiencia do Funchal. $O$ drama em 3 actos, original de Francisco Leite Bastos - GLORIAS DO TRABALHO - O entreacto comico, original de Francisco Xavier da Silva - A REVISTA A GALOPE NO ANNO DE 1864. A comedia em um acto, imitação por Guilherme Augusto Gutierre da Silva - UM TAFUL EM CALÇAS PARDAS. Entrada ás 7 e meia principia ás 8 horas. (Voz do Povo, 28/10/1869: 4)

No entanto, apenas na primeira metade do século XX emerge um elevado número de peças de teatro com música, produzidas por músicos e atores da Madeira. O período entre 1909 e 1959 constituiu a época áurea das operetas e teatros de revista regionais, que o Quadro 2 ilustra de forma não exaustiva:

\begin{tabular}{|c|c|c|c|c|c|}
\hline REVISTA & ANO & ATOS & QUADROS & MÚSICAS & NOMES DE AUTORES \\
\hline $\begin{array}{l}\text { Sciencia } \\
\text { Nova }\end{array}$ & 1909 & 3 & 9 & 45 & $\begin{array}{l}\text { Autores: Sousa Brazão e Gabriel } \\
\text { Camacho } \\
\text { Música: Alfredo Graça }\end{array}$ \\
\hline $\begin{array}{l}\text { A Madeira } \\
\text { por dentro }\end{array}$ & 1915 & 2 & 6 & 25 & $\begin{array}{l}\text { Autores: J. do Amaral e E. V. (Feyo) } \\
\text { Música: Manoel Ribeiro }\end{array}$ \\
\hline $\begin{array}{l}\text { A Madeira } \\
\text { na berlinda }\end{array}$ & 1916 & 3 & 12 & $\begin{array}{c}28 \\
\text { (1. }{ }^{a} \text { versão) } \\
32 \\
\text { (2. versão) }\end{array}$ & $\begin{array}{l}\text { Autores: Francisco Bento e Gouveia } \\
\text { e Luiz Pinheiro } \\
\text { Música: Manoel Ribeiro }\end{array}$ \\
\hline
\end{tabular}




\begin{tabular}{|c|c|c|c|c|c|}
\hline REVISTA & ANO & ATOS & QUADROS & MÚSICAS & NOMES DE AUTORES \\
\hline Miúdos & 1916 & 2 & 8 & $\begin{array}{c}32 \\
\left(1 .^{a} \text { versão) }\right. \\
34 \\
\text { (2. }{ }^{\text {a }} \text { versão) } \\
\end{array}$ & $\begin{array}{l}\text { Autores: Pedro C. d'Oliveira } \\
\text { Música: Dário Florez }\end{array}$ \\
\hline $\begin{array}{l}\text { Semilhae } \\
\text { alface }\end{array}$ & $\begin{array}{l}1917 / \\
1918 \\
\end{array}$ & 2 & 8 & 32 & $\begin{array}{l}\text { Autores: Adão Abreu e N. N. } \\
\text { Música: Dário Florez }\end{array}$ \\
\hline Água vai... & 1922 & & & 16 & Música: Dário Florez \\
\hline $\begin{array}{l}\text { À procura } \\
\text { da sorte... }\end{array}$ & 1925 & 1 & 9 & & $\begin{array}{l}\text { Autores: Vicente Júlio da Silva } \\
\text { Música: António Rosa de Caires }\end{array}$ \\
\hline $\begin{array}{l}\text { Gente do } \\
\text { mar }\end{array}$ & 1927 & 2 & & & $\begin{array}{l}\text { Autores: D. Eugénia Rego Pereira } \\
\text { Música: Dário Florez }\end{array}$ \\
\hline A $9 ! \ldots$ & 1934 & 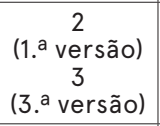 & & & $\begin{array}{l}\text { Autores: Adão Abreu } \\
\text { Música: Dário Florez }\end{array}$ \\
\hline Lá vai fogo! & 1935 & 2 & 4 & & $\begin{array}{l}\text { Autores: Adão Abreu } \\
\text { Música: Dário Florez }\end{array}$ \\
\hline $\begin{array}{l}\text { A Madeira } \\
\text { em festa }\end{array}$ & 1938 & 2 & 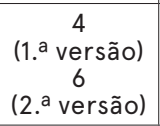 & $\begin{array}{c}16 \\
\left(1 .^{a} \text { versão) }\right. \\
22 \\
\text { (2. }{ }^{\text {a versão) }} \\
\end{array}$ & $\begin{array}{l}\text { Autores: Teodoro Silva, Capitão } \\
\text { Edmundo Lomelino } \\
\text { Música: Raul de Abreu }\end{array}$ \\
\hline $\begin{array}{l}\text { Ilha } \\
\text { encantada }\end{array}$ & 1939 & 2 & 6 & & $\begin{array}{l}\text { Autores: Dr. Correia Monteiro } \\
\text { Música: Capitão Gustavo Coelho }\end{array}$ \\
\hline Carnaval & 1939 & 2 & 8 & 20 & $\begin{array}{l}\text { Autores: Teodoro Silva e Mário B. de Abreu } \\
\text { Música: Capitão Edmundo Lomelino }\end{array}$ \\
\hline Tempestade & 1940 & 2 & & & \\
\hline S'tá quieta & 1940 & 2 & 9 & 25 & $\begin{array}{l}\text { Autores: Mário B. de Abreu e Francisco } \\
\text { Silva } \\
\text { Música: Capitão Edmundo Lomelino }\end{array}$ \\
\hline $\begin{array}{l}\text { P'ra } \\
\text { Romaria }\end{array}$ & 1940 & & & & \\
\hline $\begin{array}{l}\text { Zé do } \\
\text { Calhau }\end{array}$ & 1941 & 2 & 14 & & $\begin{array}{l}\text { Autores: F. Calado Nunes } \\
\text { Música: Sílvio Alva, Albertino Lopes } \\
\text { e Irmãos Freitas }\end{array}$ \\
\hline $\begin{array}{l}\text { Desanda a } \\
\text { roda }\end{array}$ & 1942 & & & & $\begin{array}{l}\text { Autores: Teodoro Silva } \\
\text { Música: João Serrano e Irmãos Freitas }\end{array}$ \\
\hline $\begin{array}{l}\text { Bolas de } \\
\text { sabão }\end{array}$ & 1944 & 2 & 9 & 32 & $\begin{array}{l}\text { Autores: Teodoro Silva } \\
\text { Música: Capitão Edmundo Lomelino } \\
\text { e Irmãos Freitas }\end{array}$ \\
\hline $\begin{array}{l}\text { Flores da } \\
\text { Madeira }\end{array}$ & 1945 & 2 & 8 & 27 & $\begin{array}{l}\text { Autores: Teodoro Silva e E. Feyo } \\
\text { Música: Capitão Edmundo Lomelino }\end{array}$ \\
\hline Cá e lá & 1945 & & & & $\begin{array}{l}\text { Autores: Teodoro Silva } \\
\text { Música: Capitão Edmundo Lomelino }\end{array}$ \\
\hline $\begin{array}{l}\text { Ilha de } \\
\text { sonho }\end{array}$ & 1948 & 1 & 4 & & Música: Dário Florez \\
\hline $\begin{array}{l}\text { Sónia, } \\
\text { boneca } \\
\text { encantada... }\end{array}$ & 1948 & 2 & 11 & & $\begin{array}{l}\text { Autores: Henrique Martins; versos de } \\
\text { Gonçalves Preto } \\
\text { Música: Capitão Edmundo Lomelino } \\
\text { e Antonieta Pereira }\end{array}$ \\
\hline $\begin{array}{l}\text { Sentinela } \\
\text { alerta }\end{array}$ & 1954 & & & & $\begin{array}{l}\text { Autores: Teodoro Silva } \\
\text { Música: Capitão Edmundo Silva }\end{array}$ \\
\hline $\begin{array}{l}\text { Olha p'ra } \\
\text { isto }\end{array}$ & 1958 & 2 & $\begin{array}{c}14 \\
\left(1 .^{a} \text { versão) }\right. \\
16 \\
\left(2 .^{a} \text { versão) }\right. \\
\end{array}$ & & $\begin{array}{l}\text { Autores: Calado Nunes } \\
\text { Música: Maria de Lourdes Travassos }\end{array}$ \\
\hline $\begin{array}{l}\text { Deixa } \\
\text { passar }\end{array}$ & 1959 & & & & $\begin{array}{l}\text { Autores: F. Silva } \\
\text { Música: Capitão Edmundo Lomelino }\end{array}$ \\
\hline
\end{tabular}

QUADRO 2 - TEATROS DE REVISTA MADEIRENSES ENTRE 1909 E 1959 
Segundo Luiz Rebello, no caso das produções regionais, normalmente fruto dos amadores locais, são seguidos os modelos citadinos, naturalmente com a introdução de eventos, costumes e figuras regionais e a adaptação à censura moral local. Nesta linha, além dos grandes acontecimentos, os espaços de ação e os temas do teatro de revista estão quase sempre ligados às novas modas e aos prazeres sensoriais lúdicos, tais como as festas, o sexo, a gastronomia, o jogo e/ou o desporto (Rebello, 1984:31).

Este tipo de temas encontra-se bem explícito em algumas revistas regionais. Assim, tal como em Lisboa, as intrigas do teatro de revista estavam também ligadas aos grandes acontecimentos sociais e políticos da época. Por exemplo, na revista Carnaval (1939), o autor madeirense Teodoro Silva realizou uma paródia a um acontecimento político, muito comentado na época, o Acordo de Munique (1938)2, sendo interessante esta referência, visto que Portugal viria a tomar uma posição política de neutralidade. De qualquer modo, no âmbito da investigação, não se encontraram outras notícias sobre este tema na imprensa regional, sendo difícil perceber o impacto do acontecimento na opinião pública madeirense.

Emerge também, muito claramente, nas revistas, um conjunto vasto de referências a diversos contextos específicos da realidade madeirense: crítica de costumes locais, uso de regionalismos, ou a alusão a elementos característicos da cultura local, tais como os típicos arraiais. São disso exemplo as revistas Semilha e alface (O Madeirense, 25/7/1918:3) ou A Madeira em festa (Re-nhau-nhau, 27/1/1940: 5).

O caráter humorístico de grande parte das revistas é destacado, pela imprensa coeva, como um importante fator de diversão, na vida dos Funchalenses em particular, permitindo que estes pudessem «passar horas alegres, esquecendo os aborrecimentos do ano inteiro» (Diário de Notícias, 22/2/1922: 1), desfrutando de um produto cultural intimamente ligado ao seu quotidiano.

O Quadro 3 apresenta dez números musicais, cujas letras serão seguidamente analisadas, de modo a esboçar a temática de quotidiano abordada no teatro de revista regional. É aqui importante referir que,

2 Pelo Acordo de Munique, a Inglaterra e a França cederam às intenções da Alemanha de Hitler e da Itália de Mussolini, entregando a estas nações o controlo das montanhas Sudetas e de parte da Checoslováquia (Esteireiro, 2008: 52). 


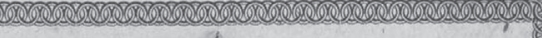

SEGUNDA-FEIRA 29 DE JULHO DE 1918

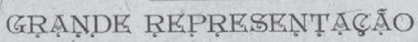

Da aplaudida Revista de costumes Madeirenses em um prologo e 2 actos

ORIGINAL DE ADAO ABREU NUNES E N. N.

Com musica do distincto Maestro amador

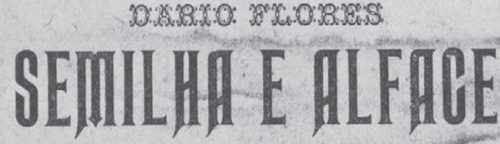

$\mathrm{Na}$ qual tomam parte as destintas amadoras

OLINDA DE SOUZA

VIOLANTE MONTANHA, BLVIRA DE SOUZA

ALICE ALVES E GABRIELA FERNANDES

Julieta Alves, Carolina Duarte,

Olivia Melim, Margarida Batista, Maria do Carmo,

Dulse Conceição, Filomena Rosa, Alice Melim, e coro geral.

E os Senhores Amancio do Quental, Dionisio Freitas, Mario Dias, Arnaldo Rebelo,

Manoel Correia, João Vieira etc.

COMPERES

Zé Alface-GABRIEL EIRAS

Maneta - JOÃO DE SOUZA

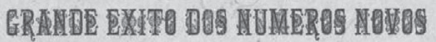

A TARANTLLA- Ilaracuáa e Parati-Persiana e fàrgarejo

Illa lingua, Intriga e Boato - Imor nas treras

$$
A \text { trincheira }
$$

2. ${ }^{a}$ APRESENTAÇÃO DO QUADRO NOVO

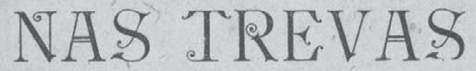

120 personagens -35 numeros de musica

Orquestra composta por 18 professor'es Direção musical de DARIO FLORES

Scenario de Fernando Camara

Contra regras - Arthur Montanha

A. Lemos e Dionisio de Freitas

TXXYOTO DOS QUXNOROS

PROLOG0 - 1. . No fundo da terra-2.0 No arehivo das revistas Primeiro acto-3.0 A' coca-4. Nas trevas - 3..$^{\circ}$ Natal (apoleose) Segundo acto - 6.0 Patos e Pegas -7.0 Palacio da evolnção $8 .^{\circ}$ - Gloria do Autor apoleose)

Entrada ás 8 horas, principiando o espectaculo ás 8 e meia (antigas) 
infelizmente, foi difícil encontrar um conjunto alargado de números musicais que permitisse maior representatividade dos estilos musicais e dos temas sociais abordados.

\begin{tabular}{|c|c|c|c|c|}
\hline N. ${ }^{\circ}$ & TÍTULO & AUTORES & GÉNERO & REVISTA \\
\hline 1 & «Miséria» & $\begin{array}{l}\text { Letra: Pedro C. Oliveira } \\
\text { Música: Dário Florez }\end{array}$ & Fado & $\begin{array}{l}\text { Revista Miúdos } \\
30 \text { de abril de } 1916\end{array}$ \\
\hline 2 & «Canção do bilhar» & $\begin{array}{l}\text { Letra: Pedro C. Oliveira } \\
\text { Música: Dário Florez }\end{array}$ & & $\begin{array}{l}\text { Revista Miúdos } \\
30 \text { de abril de } 1916\end{array}$ \\
\hline 3 & «Fumadores» & $\begin{array}{l}\text { Letra: Pedro C. Oliveira } \\
\text { Música: Dário Florez }\end{array}$ & Habanera & $\begin{array}{l}\text { Revista Miúdos } \\
30 \text { de abril de } 1916\end{array}$ \\
\hline 4 & $\begin{array}{l}\text { «As bordadeiras } \\
\text { - Vime e bordado» }\end{array}$ & $\begin{array}{l}\text { Letra: Pedro C. Oliveira } \\
\text { Música: Dário Florez }\end{array}$ & & $\begin{array}{l}\text { Revista Miúdos } \\
30 \text { de abril de } 1916\end{array}$ \\
\hline 5 & «Par ditoso» & $\begin{array}{l}\text { Letra: Pedro C. Oliveira } \\
\text { Música: Dário Florez }\end{array}$ & Valsa & $\begin{array}{l}\text { Revista Miúdos } \\
30 \text { de abril de } 1916\end{array}$ \\
\hline 6 & «O emigrante» & $\begin{array}{l}\text { Letra: Mário Alves } \\
\text { Música: Edmundo da C. Lomelino }\end{array}$ & & $\begin{array}{l}\text { Revista Sol de Inverno } \\
\text { Maio de } 1938\end{array}$ \\
\hline 7 & «Cega-rega» & $\begin{array}{l}\text { Letra: Mário Alves } \\
\text { Música: Raúl Abreu }\end{array}$ & & Revista Funchal na lua \\
\hline 8 & $\begin{array}{l}\text { «Vestido de seda } \\
\text { e smoking» }\end{array}$ & $\begin{array}{l}\text { Letra: Mário Alves } \\
\text { Música: Raúl Abreu }\end{array}$ & Foxtrot & Revista Funchal na lua \\
\hline 9 & «Borboletas» & $\begin{array}{l}\text { Letra: Mário Alves } \\
\text { Música: Raúl Abreu }\end{array}$ & Tango & Revista Funchal na lua \\
\hline 10 & $\begin{array}{l}\text { «Canção da } \\
\text { meia-noite» }\end{array}$ & $\begin{array}{l}\text { Letra: Mário Alves } \\
\text { Música: Raúl Abreu }\end{array}$ & $\begin{array}{l}\text { Fox- } \\
\text {-canção }\end{array}$ & Revista Funchal na lua \\
\hline
\end{tabular}

QUADRO 3 - ALGUNS NÚMEROS MUSICAIS DO TEATRO DE REVISTA MADEIRENSE

Os dados analisados permitem-nos perceber linhas de pensamento da época, que evidenciam a alta sociedade madeirense como consumidora dos espetáculos de revista levados a efeito na Madeira. A imprensa escrita salienta comummente que os espetáculos são frequentados pelas «famílias mais distintas da sociedade funchalense» (Diário de Notícias, 1/6/1915: 2). Deduz-se, portanto, que o teatro de revista seria idealizado tendo em conta a elite da sociedade como seu público-alvo. Esta circunstância não se verificava em Lisboa, local onde as revistas configuravam um cariz mais popular, abrangendo de uma forma mais equilibrada um «leque da pequena à alta burguesia» (Rebello, 1984: 28). Possivelmente, a ausência de uma tradição operática no Funchal terá contribuído para que o género revista tivesse uma aceitação elevada junto da elite funchalense.

De acordo com o que vimos referindo, relativamente aos temas das revistas, apresentam-se a seguir alguns excertos de quadras pertencentes a números musicais, de modo a ilustrar o tipo de temas abordados nas peças madeirenses. 


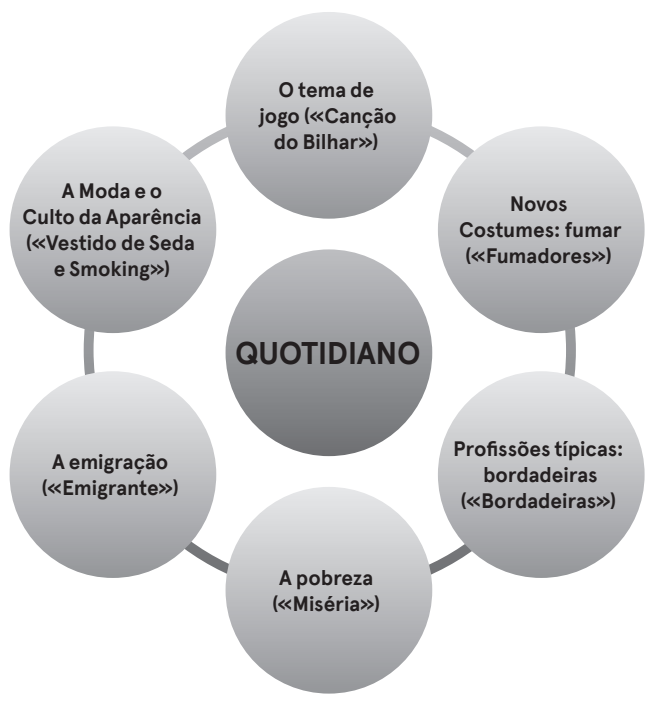

FIGURA 2 - TEMAS ABORDADOS EM NÚMEROS MUSICAIS DE TEATROS DE REVISTA MADEIRENSES

Este tema aparece, por exemplo, na revista Miúdos, estando bem presente no número «Canção do bilhar». Neste caso, são explícitas as referências ao tema do jogo como forma de diversão e de entretenimento, ao mesmo tempo que se alude à respeitabilidade das jovens da alta sociedade, nos jogos de sedução amorosa. Associadas às referências neste plano caracterizador da sociedade, surgem, neste caso específico, as naturais referências às regras do jogo como forma de complementar a própria canção:

Toda a jovem d'alta linha,

Com nobreza, com decoro,

Joga a sua partidinha

Com o belo do namoro.

Se o joguinho for ao meio

Devemos na conta ter;

Se a vermelha acerta em meio

Para a branquinha perder. ${ }^{3}$

3 Excerto da letra da peça musical «Canção do bilhar», da revista Miúdos, música de Dário Florez e letra de Pedro C. Oliveira. Ver https://bibliotecadseam.madeira.gov.pt/. 
Os novos costumes da época, como fumar, também são retratados nas revistas madeirenses. Na canção «Fumadores», de algum modo, é estabelecida uma associação do novo costume de fumar, tido como muito prazeroso, com a alusão a um ténue erotismo ou romance, que o mesmo poderia propiciar:

\author{
Um cigarrinho a arder \\ Que gosto dá, \\ É singular prazer, \\ Melhor não há. \\ Suas espirais desenham \\ Noites d'amor, \\ Virgens que se despenham \\ No estertor. ${ }^{4}$
}

As profissões e os produtos considerados típicos da região também integram as revistas regionais. Na canção «Bordadeiras», dá-se destaque ao bordado da Madeira como sendo uma das atividades mais importantes e transversais à sociedade madeirense. Na verdade, o bordado não era tido como atividade que estivesse destinada a um grupo particular, sendo exercida não só por adultos, mas também por crianças. Uma questão curiosa na letra desta canção é o despique que ocorre entre o bordado e os trabalhos em vime típicos da Camacha:

VIME

Das indústrias da Madeira

É o bordado a mais catita.

És tu a mais corriqueira

a mais limpa e mais bonita.

4 Excerto da letra da canção «Fumadores», da revista Miúdos. Ver https://bibliotecadseam. madeira.gov.pt/. 
BORDADO

Vai-te embora vilãozinho,

Vai a outra freguesia.

Gosto de ti pra vizinho,

Mas não quero a companhia.

VIME

Ó borda, rica filha, borda, borda,

Ó borda, rica filha, borda bem.

Que em casa, rica filha, tudo borda,

Borda a tia, borda a mana e borda a mãe. ${ }^{5}$

Na canção «Miséria», da revista Miúdos, é possível perceber que também na primeira metade do século $\mathrm{xx}$ eram abordados os temas da miséria, do abandono e da angústia. De facto, a escolha deste tema, de um modo genérico, evidencia também a existência de alguma preocupação com os problemas da sociedade da época:

Com fome e frio, coitada!

Desgraçada!

Abandonada!

Passo a vida no meu lar...

Se um dia apareço morta

A nada importa,

À minha porta

Ninguém chegará a chorar. ${ }^{6}$

\section{A EMIGRAÇÃo}

Atendendo à realidade socioeconómica da região, compreende-se que o tema relativo à emigração surja, quase inevitavelmente, nas letras das revistas. É exemplo disso a canção «O emigrante». Nela é possível destacar

5 Excerto da letra da canção «As bordadeiras», da revista Miúdos. Ver https://bibliotecadseam. madeira.gov.pt/.

6 Excerto da letra da canção «Miséria», da revista Miúdos. Ver https://bibliotecadseam.madeira.gov.pt/. 
duas ideias principais: a assunção de que as pessoas habituadas ao trabalho árduo não viam o seu esforço recompensado e tinham a necessidade de procurar melhores condições de vida fora da sua terra; e o desejo de um futuro melhor para a família:

\author{
Emigrante, vou partir, \\ Levo uma esperança a sorrir \\ Dentro do meu coração. \\ Porque havia de chorar? \\ Porque não hei-de cantar, \\ Se vou em busca de pão?! \\ As minhas mãos calejadas, \\ Ao trabalho habituadas \\ Há-de abençoá-las Deus. \\ Para que eu, enfim, garanta, \\ Isto que levo em garganta: \\ O bom futuro dos meus. ${ }^{7}$
}

\title{
A MODA E O CULTO DA APARÊNCIA
}

A questão da preocupação com as aparências, promovendo um exercício de autoelogio relativamente à imagem que algumas pessoas construíam sobre si próprias, é também um tema presente no teatro de revista regional. Por exemplo, a canção «Vestido de seda e smoking» retrata a inversão de valores morais, em que se dá prevalência à imagem em detrimento do conhecimento. Poderá também haver uma segunda leitura decorrente do tema desta canção, em que a elite critica a burguesia ascendente, pelo facto de não ser instruída:

ELA

Eu sei pegar num cigarro

E dizer «Ai que chatice»!

Vou ao volante do carro

E toco piano e pife.

7 Excerto da canção «O emigrante», da revista Sol de Inverno. Ver https://bibliotecadseam. madeira.gov.pt/. 
ELE

Mal sei ler e escrever,

Mas das salas sou leão,

Porque cuido e a valer,

Da minha apresentação!

ELA

Com este rabo da moda,

Com este comprido rabo,

Sou a dama d'alta roda,

Irmã gémea do diabo... ${ }^{8}$

LOCAIS

O teatro de revista na Madeira ocorreu em diferentes espaços. No período em estudo, destacam-se o Teatro Circo, o Teatro Municipal Baltazar Dias $^{9}$ e o Pavilhão Paris, apesar de terem sido produzidas revistas em outros locais. O Quadro 4 apresenta os locais, destacando essencialmente três parâmetros: o local, o intervalo temporal da realização de revistas em cada um desses espaços e a quantidade de revistas produzidas.

\begin{tabular}{|l|c|c|}
\hline \multicolumn{1}{|c|}{ LOCAL } & INTERVALO TEMPORAL & QUANTIDADE DE REVISTAS \\
\hline Teatro Circo & $1914-1933$ & 34 \\
\hline Pavilhão Paris & $1914-1921$ & 21 \\
\hline Patronato de São Pedro & $1928-1938$ & 75 \\
\hline Teatro Municipal Baltazar Dias & $1909-1959$ & 18 \\
\hline Outros $^{10}$ & $1915-1928$ & 218 \\
\hline
\end{tabular}

QUADRO 4 - ESPAC̣OS DE ATUAÇÃO COM TEATRO DE REVISTA, NO PERÍODO DE 1909-1959

9 Assumimos a designação de Teatro Municipal Baltazar Dias para o intervalo temporal considerado; no entanto, este espaço possuiu diversos nomes ao longo do tempo: Teatro Dona Maria Pia, Teatro Funchalense, Teatro Dr. Manuel de Arriaga e, finalmente, Teatro Municipal Baltazar Dias (designação atual).

10 Salão Teatro Gil Vicente, Quinta dos Reis, Salão Foz, Salão Teatro dos Guerrilhas, Cine Jardim, Salão Teatro da Banda Municipal, Pavilhão Almeida Garrett, Salão Teatro dos Álamos, Salão Teatro Amenidade. 


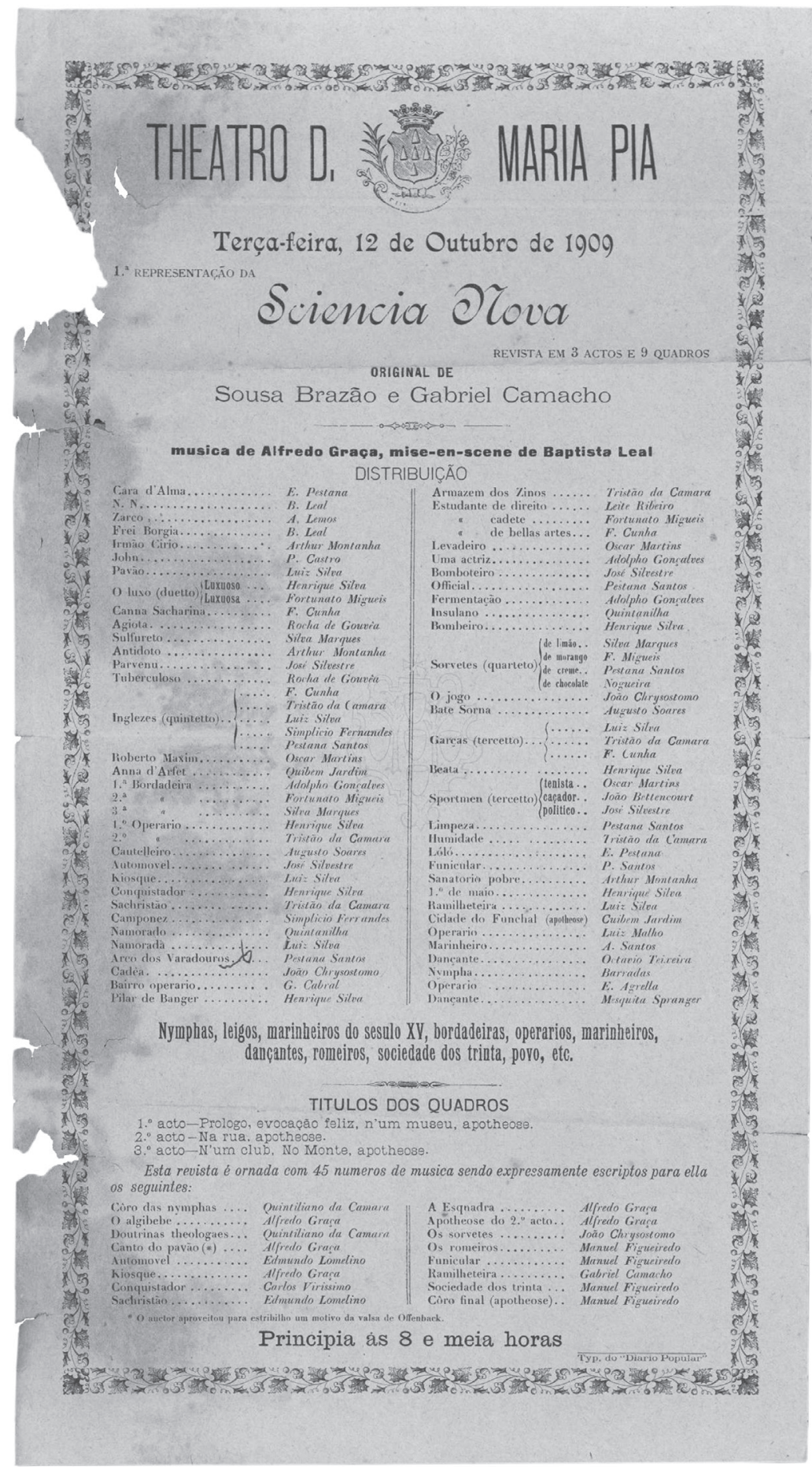


O primeiro registo que se encontrou relativamente à realização de teatro de revista, de autores madeirenses, data de 1909, no então Teatro D. Maria Pia, com a revista Sciencia nova, original de Sousa Brasão e Gabriel Camacho, com música de Augusto Graça, contramestre da Banda do Regimento de Infantaria n. ${ }^{\circ} 27$.

Assim, centrando a nossa análise nos locais onde se apresentaram revistas entre os anos de 1909 e 1959, período em que se desenvolveu maioritariamente o teatro de revista de autores madeirenses, identificou-se que os espetáculos foram realizados em quatro espaços distintos: o Teatro Circo, o Teatro Municipal Baltazar Dias, o Pavilhão Paris, e, por fim, o Patronato de São Pedro. O Teatro Circo acolheu a maior parte dos espetáculos de revista. Este espaço situava-se na placa central da Praça Marquês de Pombal, tendo sido inaugurado a 23 de outubro de 1909. Foi considerado um dos melhores espaços de diversão da época, nele tendo atuado várias companhias circenses e de variedades, que quase sempre continham pequenos excertos de peças de teatro e revistas (Carita/Melo, 1988).

Por sua vez, o Teatro Municipal Baltazar Dias, que havia sido fundado no final do século XIx, foi o espaço que durante mais anos acolheu este tipo de espetáculos. A construção deste teatro respondeu à aspiração que os Madeirenses manifestavam para que a cidade do Funchal tivesse um grande teatro, à semelhança do que acontecia em diversas cidades europeias, para mais eficazmente se ajustar às necessidades culturais (Carita/Melo, 1988).

Um outro local, o Pavilhão Paris, situado a norte da Santa Casa da Misericórdia do Funchal, muito embora tenha servido maioritariamente para sessões de cinema (Carita/Melo, 1988), foi também um espaço de exibição de um número significativo de espetáculos de revista, tal como se demonstra no Quadro 4.

Relativamente aos outros espaços, destaca-se a realização de dois espetáculos de revista no Teatro Almeida Garrett, localizado na Ribeira Brava, o que, apesar de pouco significativo em quantidade, evidencia que houve pelo menos duas representações fora da cidade do Funchal, noticiadas na imprensa. Além destes, realizaram-se ao todo 19 espetáculos dispersos por vários locais: Salão Teatro Amenidade, o Salão Teatro da Banda Municipal do Funchal e o Salão Musical 1. ${ }^{\circ}$ de Dezembro de 1926, na Quinta dos Reis (Monte), entre outros. 


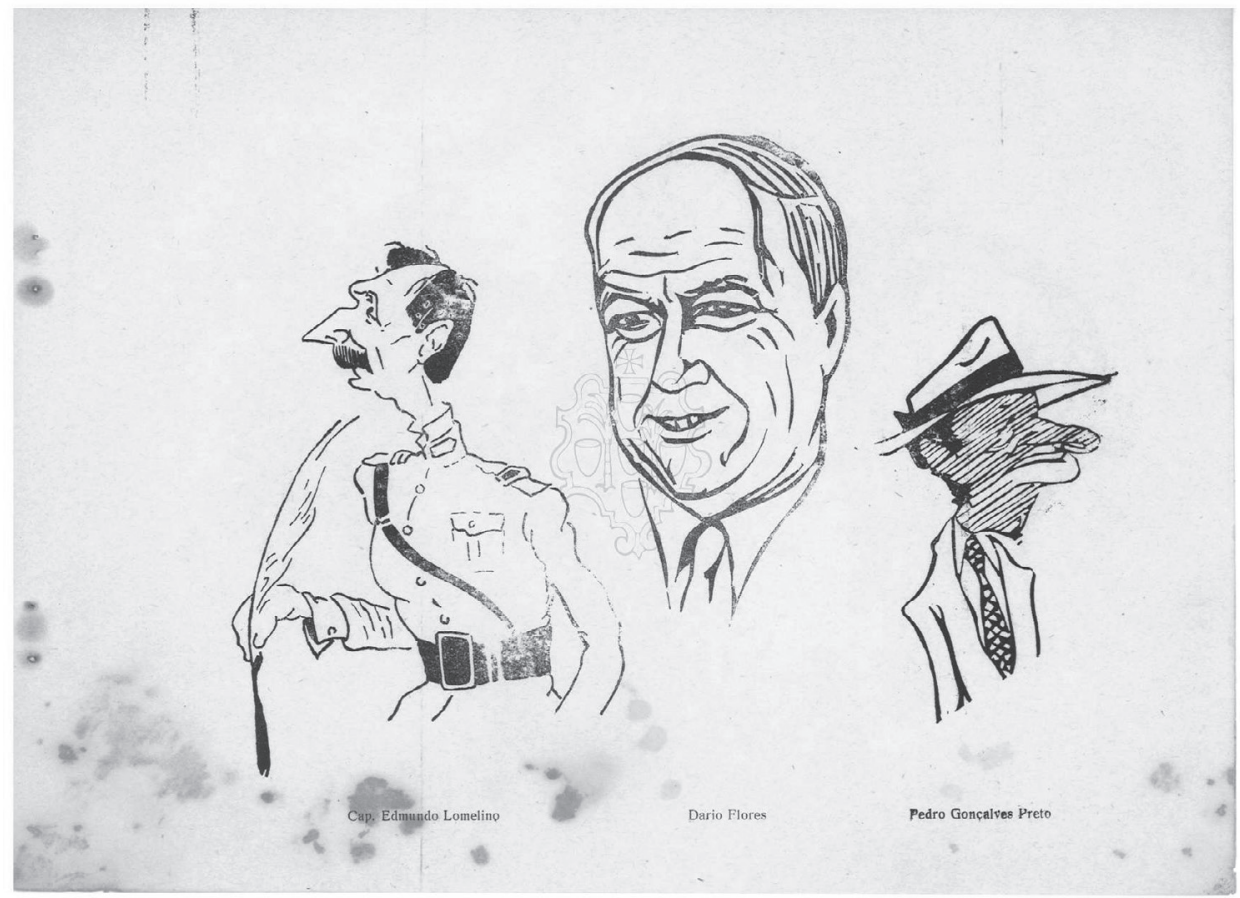

FIGURA 4 - CARICATURA DOS AUTORES EDMUNDO LOMELINO, DÁRIO FLORES E PEDRO GONC̣ALVES PRETO

Apesar de o teatro de revista ser habitualmente considerado uma arte menor, na Madeira os autores e protagonistas faziam parte do que podemos designar de uma elite local, tal como a assistência, a que já fizemos referência. Nas revistas, participavam assim académicos, militares, jornalistas e escritores, que acabavam por conferir a estes espetáculos algum glamour e uma acrescida importância em termos de representatividade na sociedade.

No caso das revistas, estas influências terão surgido principalmente por ação de alguns músicos militares provenientes do continente. No caso da zarzuela espanhola, a influência surge a partir da ação de músicos espanhóis que atuaram no Funchal nos primeiros anos de atividade do Teatro Municipal (Esteireiro, 2008). Na primeira metade do século Xx foi produzido um repertório extenso, através da ação de músicos como Augusto Graça, Manuel Ribeiro, Dário Flores, o Capitão Edmundo Conceição Lomelino e ainda os Irmãos Freitas. No domínio literário, a variedade de autores é maior, destacando-se nomes como Alberto Artur Sarmento, 
Adão Nunes e mais tarde Teodoro Silva. Na Figura 4, surgem caricaturados três dos autores de teatro de revista.

Dos autores que consideramos mais importantes na produção de revistas na Madeira, importa biografar sumariamente Dário Florez, Manuel Ribeiro, Edmundo Conceição Lomelino, Gustavo Augusto Coelho, e ainda os irmãos Freitas.

Salvador Dário Florez de Pando (Saragoça, 1879-Funchal, 1951) foi compositor e regente de orquestra durante cerca de três décadas no Funchal. Dirigiu concertos, orquestras e compôs músicas de revista, género em que foi um dos pioneiros na Madeira (Esteireiro, 2008). Em 1916, levou à cena no Teatro Municipal a sua revista Miúdos, com libreto de Pedro de Oliveira Castro. No ano seguinte, compôs a música para uma nova revista, Semilha e alface, com letra de Adão Nunes. Além destas obras, Dário Florez compôs mais duas revistas: Água-vai, representada em 1922, com texto de Adão Nunes, e Ilha de sonho, representada em 1948. A composição de sucessivas revistas conduziu à nomeação de Dário Florez como primeiro maestro da Grande Orquestra Madeirense, na década de 1920 (Esteireiro, 2008).

Outra personalidade influente foi Manuel Ribeiro(Mirandela, c. 1884-Lisboa, 1949). Criador de música para revistas e operetas, entre $1911 \mathrm{e}$ 1917, período em que desempenhou as funções de chefe da Banda Regimental do Funchal, compôs elevado número de obras, além da direção de diversos espetáculos. Entre as músicas que compôs durante a sua estada na Madeira destaca-se a partitura da opereta regional $A$ menina dos bordados, com libreto do jornalista Elmano Vieira; a revista A Madeira por dentro, coescrita por Elmano Vieira e Júlio do Amaral; o poema sinfónico As furnas do Cavallum e o Hino do Diário da Madeira. Durante a época em que esteve destacado no Funchal, Manuel Ribeiro compôs os seus primeiros poemas sinfónicos, alguns dos quais obtiveram grande sucesso e foram interpretados pelo grupo sinfónico Orquestra de Manuel Ribeiro, que atuou no Teatro Municipal do Funchal (Esteireiro, 2008).

Um nome que também merece destaque foi Edmundo Conceição Lomelino (Funchal, 1886-1962), uma das principais personalidades musicais da revista madeirense, compondo a maior parte das revistas representadas no Funchal entre 1930 e 1940. As suas revistas alcançaram grande sucesso no Funchal, esgotando muitas das récitas no Teatro Municipal. Das suas inúmeras composições, destacam-se Água benta, A Primavera, A Madeira em festa (1938), Carnaval (1939), Bolas de sabão (1944) e Flores da Madeira (Esteireiro, 2008). 


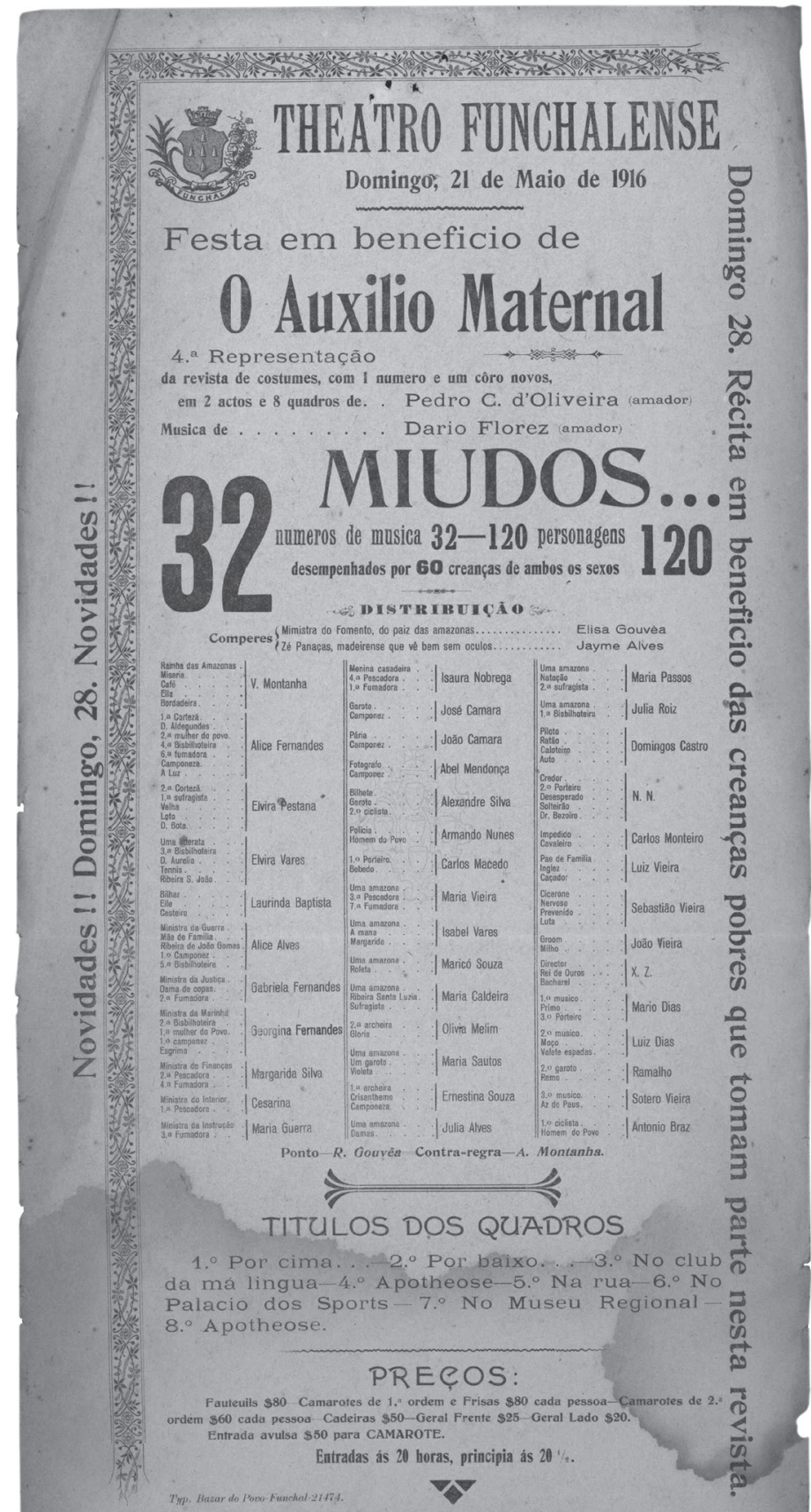

Domingo 28. Beneficio dos miudos pobres. 
Gustavo Augusto Coelho (Alcácer do Sal, 1890-Lisboa, 1965) foi um conceituado regente de bandas filarmónicas, orquestras e grupos corais, assim como prolífico compositor e transcritor de música. Foi também chefe da banda de música do Comando Militar da Madeira e integrou o corpo docente da Academia de Música, Belas-Artes e Línguas da Madeira. Além da filarmónica Artístico Funchalense, Gustavo Coelho marcou a produção dramático-musical regional do segundo quartel do século $\mathrm{xx}$, com presença em sociedades artísticas e culturais, para as quais produziu peças instrumentais, nomeadamente para uma revista de variedades da autoria de Adão Nunes, apresentada pela Academia Funchalense, no Teatro Municipal, em 1929.

Além dos nomes acima referidos, destacaram-se ainda no domínio do teatro de revista madeirense os irmãos Freitas. Os três irmãos - José (1914-1973), Rufino (1916-1986) e Mário (1920-1978) - tocavam em muitas festas populares, como bailes de Carnaval, São João, ou chás dançantes no Ateneu ou na Quinta Vigia. A combinação de instrumentos da tradição popular madeirense com os convencionais de uma cultura musical urbana, tais como o piano, baixo, viola, violino e flauta travessa ou, nalguns casos, a bateria, arranjada de forma moderna para a época, resultou numa sonoridade inovadora, de cariz mais popular. As suas produções musicais, quer editadas em disco, quer apresentadas na revista Rosário de cantigas, foram fundamentais para o sucesso e popularidade alcançados no meio funchalense. A Valentim de Carvalho, conhecendo o sucesso destes músicos, deslocou-se à Madeira para proceder ao seu registo discográfico (Camacho, 2008).

A partir da análise dos dados recolhidos, verifica-se um conjunto de considerações finais que merecem ser sublinhadas. Desde logo, o facto de emergir uma realidade pouco conhecida, que aponta para uma significativa produção cultural no intervalo temporal considerado. De facto, para a efetivação das centenas de produções de espetáculos de revista levados a efeito na Madeira, verificou-se todo um conjunto de procedimentos do ponto de vista logístico das companhias e das composições musicais que nos permite reconhecer, além da importância que assumiram do ponto de vista social e cultural, a complexidade e elevada qualidade dos eventos, como é explícito em algumas reações da imprensa. 
Acreditamos que existiu uma produção relevante de originais de teatro de revista na Madeira, que exerceu um forte impacto na sociedade do seu tempo.

A representatividade cultural, relacionada com a realidade local, plasmada nas letras das canções e nos temas genéricos das revistas, é outro interessante apontamento a destacar. Como se pode verificar, assuntos como o bordado madeirense, a indústria dos vimes, os jogos tradicionais, os arraiais típicos, as pescas, entre outros, serviram de base temática para muitos dos espetáculos de revista na Madeira. Este aspeto permite-nos considerar que estes temas mais regionais adquiriram uma acrescida importância no contexto geral da idealização e produção das revistas, afastando um pouco a ideia de que os teatros de revistas na Madeira, do ponto de vista temático, pudessem ser unicamente uma replicação do que acontecia em Lisboa.

A análise relativa aos locais onde se realizaram as revistas é também reveladora de algumas interessantes leituras que se podem traçar. Deste modo, tal como referido, o Teatro Municipal Baltazar Dias não foi o local onde mais produções de teatro de revista foram levadas à cena, mas o Teatro Circo, e, em terceiro lugar, o Pavilhão Paris.

Tal permite-nos supor que, não obstante o facto de o consumidor final dos espetáculos ter sido maioritariamente constituído pela elite madeirense, que veria o Teatro Municipal como o que melhor responderia às suas características elitistas, a produção dos espetáculos de revista na Madeira foi muito bem acolhida em diversos sítios, sobretudo no Funchal. Relacionada com esta questão, reforçamos o que referimos relativamente à assistência aos espetáculos: grande parte das produções eram muito concorridas, registando-se, em diversas vezes, lotações esgotadas.

Este artigo configura apenas um primeiro ensaio sobre um assunto ainda pouco estudado. Existe assim um conjunto de questões a que apetecia responder nesta primeira fase da investigação, não existissem limitações temporais e de documentação disponível. Foi notório que, no estado atual do repertório disponível, não se torna fácil caracterizar, de forma séria e com base numa análise musical sistemática, as obras dos compositores encontrados. De igual forma, a ausência dos textos das revistas não permite compreender aprofundadamente de que modo estas refletiam os problemas sociais e políticos da época, bem como retirar conclusões sobre a sua qualidade literária. Assim, terminamos com um conjunto de questões, que aqui deixamos como pistas para investigações subsequentes. O que reflete o teatro de revista madeirense do 
contexto político e social? De que modo se alterou consoante os diferentes regimes políticos ao longo da primeira metade do século $\mathrm{xx}$ (monarquia, república, Estado Novo)? Qual a qualidade literária dos textos? Como se caracterizam musicalmente as obras dos diferentes compositores? Que tipo de géneros musicais foram privilegiados (fado, maxixe, foxtrots, valsas, marchas, etc.)? Qual a receção da crítica musical e que tipo de censura existia? Como podemos comparar o teatro de revista madeirense com o teatro de revista de outras localidades de Portugal e do Brasil?

\section{REFERÊNCIAS BIBLIOGRÁFICAS}

«A Escola Industrial», Re-nhau-nhau, 27 de Janeiro de 1940, Funchal, p. 5 .

BAstos, António Sousa (1908), Diccionario do Theatro Portuguez, Lisboa, Libânio da Silva.

BERJEAUT, Simon (2005), Le théâtre de revista: un phénomène culturel portugais (1851-2005), Paris, L'Harmattan.

САмасно, Rui (2008), «Irmãos Freitas», in Paulo Esteireiro (coord.), so Histórias de músicos na Madeira, Funchal, 500 Anos e Associação de Amigos do Gabinete Coordenador de Educação Artística.

CARita, Rui e Melo, Luís (1988), 100 anos do Teatro Municipal Baltazar Dias: 11 de Março 1888-1988, Funchal, Câmara Municipal.

CLODE, Luiz Peter (1983), Registo bio-bibliográfico de Madeirenses: séculos XIX e XX, Funchal, Caixa Económica do Funchal.

ESTEIREIRo, Paulo (2008), «Edmundo da Conceição Lomelino», in 5o Histórias de músicos na Madeira, Funchal, 500 Anos e Associação de Amigos do Gabinete Coordenador de Educação Artística, p. 52.

FERREIRA, Andrade (1860), Os melhoramentos materiais, comédia satyrica e fantasmagórica em 3 actos e 4 quadros, Lisboa, Typ. de Joaquim Germano de Sousa Neves.

«Festas de Carnaval», in Diário de Notícias, 22 de fevereiro de 1922, Funchal, p. 1.

«Música», in Diário de Notícias, 16 de abril de 1893, Funchal, p. 2.

PINTo, Rui Magno (2008), «Gustavo Coelho», in Paulo Esteireiro (coord.), 50 Histórias de músicos na Madeira, Funchal, 500 Anos e Associação de Amigos do Gabinete Coordenador de Educação Artística, pp. 57-59.

REBElLO, Luiz Francisco (1984-1985), História do Teatro de Revista em Portugal, 2 vols., Lisboa, Publicações Dom Quixote.

SAnTos, Graça dos (2009), «Rir para enganar o olhar do censor», Sinais de Cena, n. ${ }^{\circ}$ 12, Lisboa, Húmus, pp. 33-35. «Teatro Arriaga», in O Madeirense, 25 de julho de 1918, Funchal, p. 3.

«Theatro Esperança - Sociedade Recreio Artistico», in A Voz do Povo, 28 de outubro de 1869, Funchal, p. 4.

«Teatro Funchalense - A Madeira por dentro», in Diário de Notícias, 1 de junho de 1915, Funchal, p. 2.

«Teatro Funchalense - Miúdos», in Diário de Notícias, 23 de maio de 1916, Funchal, p. 2. 


\section{PAULO ESTEIREIRO}

É doutorado em Ciências Musicais pela Universidade Nova de Lisboa. Entre as suas publicações destacam-se As Artes Performativas no Funchal, Estudos sobre Educação e Cultura, Uma História Social do Piano e Músicos Interpretam Camões. É director da Revista Portuguesa de Educação Artística e coordenador da colecção «Madeira Música».

\section{ROGÉRIO BARROS}

É mestre em Gestão Cultural pela Universidade da Madeira e doutorado em Multimédia em Educação (Universidade de Aveiro). Tem trabalhos publicados em revistas científicas internacionais no âmbito das Ciências da Educação e participa regularmente em congressos, com comunicações em torno de questões ligadas à educação e cultura. 